\title{
Biochemical studies in Nevin-Jones syndrome
}

\author{
K. VALMIKINATHAN AND J. N. CUMINGS \\ From the Department of Chemical Pathology, Institute of Neurology, Queen Square, London
}

SUMMARY The lipid profiles of the brain in four cases of Nevin-Jones syndrome are described. A loss of phosphatidyl ethanolamine was found in both white matter and cortex in two cases as well as a more general loss of lipids in the cortex in one patient; there was a normal cerebrosidesulphatide ratio in myelin. These findings indicate a general loss of myelin over a period of time. The distribution of fatty acids in cerebrosides and sulphatides show a slight reduction in nervonic acid $(24: 1)$. The findings support the view that a secondary demyelination is present.

In 1954 Jones and Nevin described two cases showing clinically a rapidly fatal condition in which myoclonic epilepsy was a feature. Histologically there was cortical damage with status spongiosus; a vascular aetiology was postulated. Further cases were described six years later (Nevin, McMenemey, Behrman, and Jones, 1960) under the title of subacute spongiform encephalopathy. This condition is recognized by both neurologists and neuropathologists but no biochemical studies would appear to have been made. We have had the opportunity to examine material from four brains and the results are presented here.

\section{MATERIAL AND METHODS}

Four brains were removed at necropsy from patients aged $48,60,64$, and 63 , the two younger being males, who clinically had suffered from the typical features of the Nevin-Jones syndrome including myoclonus. Histological examination later verified the nature of the disorder. From each brain, portions of both white matter and cerebral cortex were obtained and examined by the procedures usually employed for lipid analyses. Water content, total phospholipid, total and esterified cholesterol, total cerebroside, hexosamine, and $\mathrm{N}$-acetyl neuraminic acid were estimated as previously (Cumings, Grundt, and Yanagihara, 1968a). Thin-layer chromatography was performed (Müldner, Wherrett, and Cumings, 1962) and phosphorus estimations made on individual lipids, using the method employed by Cumings, Shortman, and Skrbic (1965). An analysis of the fatty acids in cerebrosides and sulphatides of the brain of one case (L.H., female, 63) was performed by the technique used by Yanagihara and Cumings (1969a).

In addition, myelin was prepared from the cerebral white matter except that the final centrifugation was $28,000 \mathrm{~g}$ for four hours, and sphingolipids and cholesterol were estimated (Cumings, Thompson, and Goodwin, 1968b).

\section{RESULTS}

The results of the lipid analyses of all four cases are recorded in Table 1, showing also the findings in a normal control, examined at the same time, and which are similar to those previously reported. Relatively little abnormality is seen except in the fourth case (L.H.) where there is some loss of phospholipid and of cholesterol, more marked in the cortex than in the white matter.

Table 2 shows the relative amounts of individual phospholipids as a percentage of the total $\mathbf{P}$ in two cases compared with the same normal control as previously. Ethanolamine in the white matter and cortex is somewhat reduced, as has been found in other forms of demyelination (Yanagihara and Cumings, 1968, 1969b) involving the white matter.

The myelin of the white matter was examined with the results seen in Table 3 and very little difference from normal figures (Cumings, 1970) was found, but it was noted that relatively less myelin was obtained from a given amount of white matter than is usual. The cerebroside to sulphatide ratio is almost normal.

The results of the fatty acid composition of non-hydroxy and hydroxy fatty acids of cerebrosides and sulphatides of a normal control and one case of Nevin-Jones syndrome (L.H.) are presented in Tables 4 and 5, together with the findings of Svennerholm and Ställberg-Stenhagen (1968) and of O'Brien and Sampson (1965) in normals. The fatty acid pattern of cerebroside and sulphatide of the normal control is very similar to the values 299 
TABLE 1

CEREBRAL LIPIDS IN THE NEVIN-JONES SYNDROME

\begin{tabular}{|c|c|c|c|c|c|c|c|c|c|c|}
\hline & \multicolumn{5}{|c|}{ White } & \multicolumn{5}{|c|}{ Cortex } \\
\hline & $\begin{array}{l}\text { D.S. } \\
M 48\end{array}$ & $\begin{array}{l}W . F . \\
M 60\end{array}$ & $\begin{array}{l}L . T . \\
F 64\end{array}$ & $\begin{array}{l}L . H . \\
\text { F } 63\end{array}$ & $\begin{array}{c}\text { Normal } \\
\text { S.B. } \\
M 65\end{array}$ & $\begin{array}{c}D . S . \\
M 48\end{array}$ & $\begin{array}{l}W . F . \\
M 60\end{array}$ & $\begin{array}{l}L . T . \\
F 64\end{array}$ & $\begin{array}{l}\text { L.H. } \\
\text { F } 63\end{array}$ & $\begin{array}{c}\text { Normal } \\
\text { S.B. } \\
M 65\end{array}$ \\
\hline $\begin{array}{l}\text { Total phospholipid } \\
\text { Total cholesterol } \\
\text { Esterified cholesterol } \\
\text { Total hexose as cerebroside } \\
\text { Hexosamine } \\
\text { N-acetyl neuraminic acid } \\
\text { Water }(\%)\end{array}$ & $\begin{array}{r}26 \cdot 10 \\
10 \cdot 30 \\
0 \cdot 24 \\
0 \cdot 20 \\
71 \cdot 8\end{array}$ & $\begin{array}{c}27 \cdot 4 \\
10 \cdot 2 \\
0 \cdot 66 \\
12 \cdot 2 \\
0 \cdot 34 \\
69 \cdot 8\end{array}$ & $\begin{array}{c}22 \cdot 6 \\
11 \cdot 3 \\
1 \cdot 2 \\
11 \cdot 6 \\
0 \cdot 32 \\
70 \cdot 0\end{array}$ & $\begin{array}{l}19 \cdot 7 \\
6 \cdot 9 \\
0 \cdot 14 \\
7 \cdot 7 \\
0 \cdot 35 \\
71 \cdot 8\end{array}$ & $\begin{array}{c}24 \cdot 7 \\
12 \cdot 0 \\
0 \cdot 35 \\
12 \cdot 5 \\
0 \cdot 26 \\
68 \cdot 1\end{array}$ & $\begin{array}{l}0.29 \\
86 \cdot 2\end{array}$ & $\begin{array}{l}23 \cdot 1 \\
5 \cdot 86 \\
0 \\
4 \cdot 83 \\
0 \cdot 15 \\
83 \cdot 8\end{array}$ & $\begin{array}{c}21 \cdot 4 \\
6 \cdot 0 \\
0 \cdot 8 \\
4 \cdot 9 \\
0 \cdot 75 \\
0 \cdot 2 \\
83 \cdot 2\end{array}$ & $\begin{array}{l}16 \cdot 2 \\
4 \cdot 2 \\
0 \cdot 4 \\
2 \cdot 1 \\
0 \cdot 58 \\
0 \cdot 13 \\
81 \cdot 4\end{array}$ & $\begin{array}{l}22 \cdot 8 \\
5 \cdot 37 \\
0 \cdot 2 \\
4 \cdot 06 \\
0 \cdot 61 \\
0 \cdot 2 \\
84 \cdot 5\end{array}$ \\
\hline
\end{tabular}

Results in $\mathrm{g} / 100 \mathrm{~g}$ dry tissue.

TABLE 2

CEREBRAL PHOSPHOLIPIDS IN THE NEVIN-JONES SYNDROME

\begin{tabular}{|c|c|c|c|c|c|c|}
\hline \multirow[b]{2}{*}{ Phospholipid } & \multicolumn{3}{|c|}{ White } & \multicolumn{3}{|c|}{ Cortex } \\
\hline & $\begin{array}{l}L . T . \\
F 64\end{array}$ & $\begin{array}{l}\text { L.H. } \\
F 63\end{array}$ & $\begin{array}{c}\text { Normal } \\
\text { S.B. } \\
M 65\end{array}$ & $\begin{array}{l}L . T . \\
F 64\end{array}$ & $\begin{array}{l}\text { L.H. } \\
F 63\end{array}$ & $\begin{array}{c}\text { Normal } \\
\text { S.B. } \\
\text { M } 65\end{array}$ \\
\hline Cardiolipin & $5 \cdot 1$ & $4 \cdot 5$ & 4.9 & $9 \cdot 1$ & $4 \cdot 0$ & $4 \cdot 6$ \\
\hline Phosphatidic acid & $3 \cdot 6$ & $3 \cdot 4$ & $3 \cdot 1$ & $2 \cdot 0$ & $1 \cdot 5$ & $3 \cdot 1$ \\
\hline Ethanolamine & $29 \cdot 4$ & $30 \cdot 7$ & $34 \cdot 8$ & $20 \cdot 1$ & $27 \cdot 7$ & $31 \cdot 3$ \\
\hline Serine & $15 \cdot 6$ & $15 \cdot 6$ & $18 \cdot 6$ & $8 \cdot 3$ & $19 \cdot 1$ & $16 \cdot 7$ \\
\hline Lecithin & $16 \cdot 5$ & 23.0 & $21 \cdot 4$ & $26 \cdot 0$ & $32 \cdot 4$ & $33 \cdot 0$ \\
\hline Lysoethanolamine & $4 \cdot 2$ & $3 \cdot 4$ & $2 \cdot 4$ & $4 \cdot 6$ & $3 \cdot 7$ & $2 \cdot 2$ \\
\hline Sphingomyelin & $12 \cdot 6$ & $14 \cdot 6$ & $14 \cdot 0$ & $13 \cdot 9$ & $8 \cdot 0$ & $9 \cdot 0$ \\
\hline Lysolecithin & $6 \cdot 0$ & $4 \cdot 8$ & 0.7 & $7 \cdot 0$ & $3 \cdot 6$ & 0 \\
\hline
\end{tabular}

Results as \% of total phospholipid.
TABLE 3

MYELIN LIPIDS

\begin{tabular}{lc}
\multicolumn{2}{c}{$L . H ., F 63$} \\
\hline Cerebroside $\mathrm{g} / 100 \mathrm{~g}$ myelin & $24.99(24 \cdot 4)$ \\
Sulphatide $\mathrm{g} / 100 \mathrm{~g}$ myelin & $5 \cdot 74(5 \cdot 4)$ \\
Cholesterol g/100 g myelin & $13 \cdot 3(16 \cdot 3)$ \\
Cerebroside/sulphatide ratio & $4 \cdot 4 / 1(4 \cdot 5 / 1)$ \\
Water content cerebral white matter & $71 \cdot 8 \%$
\end{tabular}

Normal results in parentheses (Cumings, 1970).

TABLE 4

NON-HYDROXY ACIDS IN CEREBROSIDES AND SULPHATIDES

(EXPRESSED AS MOLAR \%)

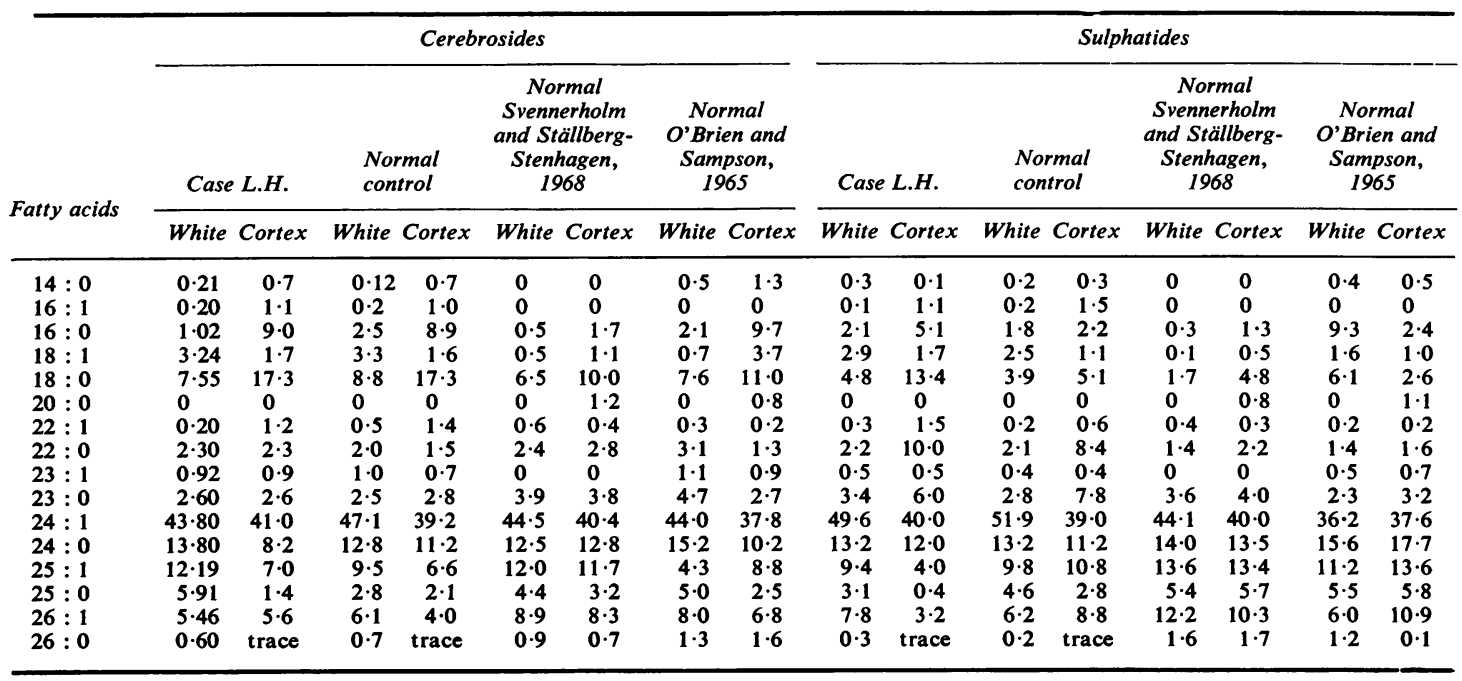


TABLE 5

HYDROXY ACIDS IN CEREBROSIDES AND SULPHATIDES IN WHITE MATTER (EXPRESSED AS MOLAR \%)

\begin{tabular}{|c|c|c|c|c|c|c|c|c|}
\hline \multirow[b]{2}{*}{ Fatty acids } & \multicolumn{4}{|c|}{ Cerebrosides } & \multicolumn{4}{|c|}{ Sulphatides } \\
\hline & Case L.H. & Normal & $\begin{array}{c}\text { Normal } \\
\text { Svennerholm } \\
\text { and Ställberg- } \\
\text { Stenhagen, } \\
1968\end{array}$ & $\begin{array}{c}\text { Normal } \\
\text { O'Brien and } \\
\text { Sampson, } \\
1965\end{array}$ & Case L.H. & Normal & $\begin{array}{c}\text { Normal } \\
\text { Svennerholm } \\
\text { and Ställberg- } \\
\text { Stenhagen, } \\
1968\end{array}$ & $\begin{array}{c}\text { Normal } \\
\text { O'Brien and } \\
\text { Sampson, } \\
1965\end{array}$ \\
\hline $14: 0$ & 0 & 0 & 0 & 0.6 & 0 & 0 & 0 & $2 \cdot 4$ \\
\hline $16: 1$ & 0 & 0 & 0 & 0 & 0 & 0 & 0 & 0 \\
\hline $16: 0$ & 0.8 & 0.7 & 0 & $1 \cdot 0$ & 0.7 & $1 \cdot 1$ & 0 & $6 \cdot 3$ \\
\hline $18: 1$ & 0 & 0 & 0 & 0.3 & 0 & 0 & 0 & 0.5 \\
\hline $18: 0$ & 0 & 0 & 0.6 & 0.6 & 0 & 0 & $0 \cdot 2$ & $2 \cdot 2$ \\
\hline $22: 1$ & 0 & 0 & 0 & 0 & 0 & 0 & 0 & 0 \\
\hline $22: 0$ & $8 \cdot 3$ & $8 \cdot 7$ & $6 \cdot 5$ & $11 \cdot 0$ & $8 \cdot 4$ & $5 \cdot 4$ & $4 \cdot 2$ & $13 \cdot 2$ \\
\hline $23: 1$ & 0 & 0 & 0 & 0 & 0 & 0 & 0 & 0 \\
\hline $23: 0$ & $18 \cdot 1$ & $18 \cdot 7$ & $17 \cdot 4$ & $13 \cdot 0$ & $17 \cdot 4$ & $16 \cdot 0$ & $14 \cdot 3$ & $11 \cdot 4$ \\
\hline $24: 1$ & $22 \cdot 5$ & $20 \cdot 2$ & $17 \cdot 9$ & 24.0 & $21 \cdot 3$ & 20.0 & $15 \cdot 3$ & $8 \cdot 4$ \\
\hline $24: 0$ & $35 \cdot 2$ & $37 \cdot 4$ & 40.0 & $34 \cdot 0$ & $41 \cdot 4$ & $43 \cdot 8$ & $42 \cdot 3$ & $46 \cdot 2$ \\
\hline $25: 1$ & 5.0 & $5 \cdot 0$ & $4 \cdot 3$ & $3 \cdot 0$ & $3 \cdot 5$ & $4 \cdot 8$ & $5 \cdot 5$ & $5 \cdot 4$ \\
\hline $25: 0$ & $6 \cdot 4$ & $6 \cdot 0$ & $6 \cdot 5$ & $4 \cdot 0$ & $4 \cdot 3$ & $6 \cdot 7$ & $8 \cdot 6$ & trace \\
\hline $26: 1$ & $3 \cdot 8$ & $3 \cdot 4$ & $4 \cdot 8$ & $4 \cdot 1$ & $2 \cdot 5$ & $2 \cdot 7$ & $6 \cdot 5$ & trace \\
\hline $26: 0$ & 0.6 & 0.5 & $1 \cdot 1$ & $2 \cdot 7$ & 0.4 & 0.6 & $1 \cdot 9$ & trace \\
\hline
\end{tabular}

reported earlier (O'Brien and Sampson, 1965; Svennerholm and Ställberg-Stenhagen, 1968; Yanagihara and Cumings, 1969a). No marked variation in the fatty acid pattern of cerebroside and sulphatide in the case of Nevin-Jones syndrome is noted as compared with the normal control. However, a slightly decreased ratio of nervonic acid $(24: 1)$ to lignoceric acid $(24: 0)$ is observed in the white matter cerebroside, and this is largely due to a reduction in nervonic acid $(24: 1)$ in cerebroside.

\section{DISCUSSION}

The importance of cerebrosides and sulphatides among the cerebral lipids is well recognized. In myelin, the ratio of cerebroside to sulphatide is remarkably constant at about 4.5 to 1 , and the cerebroside levels are frequently used as an index of myelination. The composition of these two myelin lipids has been shown to be altered in conditions such as metachromatic leucodystrophy, Krabbe's disease, and multiple sclerosis (Cumings et al., 1968b; Cumings and Goodwin, 1968). Structural changes as a decrease in C24 fatty acids in cerebroside and sulphatide have also been reported both in primary and secondary demyelinating diseases.

The present study with cases of Nevin-Jones syndrome has revealed certain interesting facts. In one case (L.H.) there was some loss of phospholipid and cholesterol which was more marked in the cortex than in the white matter. The ethanolamine fraction was somewhat reduced in the white matter and the cortex, as has been found in other forms of demyelination (Yanagihara and Cumings, 1968, 1969b) which involves the white matter. However, no marked abnormality was noted in the myelin of white matter as compared with normals, but relatively less myelin was obtained from the white matter than usual.

The slight reduction in such myelin lipids as cholesterol and the phospholipids, which was more pronounced in the cortex than in the white matter, indicates a primary pathology in the cortex in case L.H. This aspect is paralleled by the observed histological picture of a marked loss of neurones from the frontal cortex and a proliferation of astrocytes. Fatty acid analysis has revealed no gross variation in the fatty acid distribution of cerebroside and sulphatide as compared with the normals. There is, however, a slight reduction of C24 fatty acids, particularly nervonic acid $(24: 1)$ in the cerebrosides, indicating a secondary demyelination in the white matter, as shown by previous studies (Yanagihara and Cumings, 1968, 1969a).

A similar picture has been observed in Down's syndrome where there is variation in certain myelin lipids (Stephens and Menkes, 1969), as frontal lobe cholesterol content, with no alteration in the fatty acid distribution of cerebroside and sulphatide. Similarly, variations in the levels of cerebroside in the demyelinated areas of the brain associated with oedema have been reported (Yanagihara and Cumings, 1968, 1969a) when there was a slight lowering of $\mathrm{C} 24$ fatty acids in the white matter cerebroside.

The results of the present study with cases of the Nevin-Jones syndrome indicate some demyelination as suggested by the altered pattern of cholesterol 
and ethanolamine, more pronounced in the cortex than in the white matter. The demyelination is of a secondary nature as no gross abnormality, except a slight lowering of $\mathrm{C} 24$ fatty acids in cerebroside, is observed in the fatty acid pattern of cerebroside and sulphatide, and this may be due to some type of metabolic disturbance which may be non-specific in character.

One of us (K.V.) is a British Council Scholar and our thanks are given for this support.

\section{REFERENCES}

Cumings, J. N. (1970). Lipid profiles in purified myelin from control and multiple sclerosis brain tissue. Communication to 2nd International Meeting of the International Society for Neurochemistry, Milan, to be published in Riv. Pat. nerv. ment.

Cumings, J. N., and Goodwin, H. (1968). Sphingolipids and phospholipids of myelin in multiple sclerosis. Lancet, 2, 664-665.

Cumings, J. N., Grundt, I. K., and Yanagihara, T. (1968a). Lipid changes in the brain in phenylketonuria. J. Neurol. Neurosurg. Psychiat., 31, 334-337.

Cumings, J. N., Shortman, R. C., and Skrbic, T. (1965). Lipid studies in the blood and brain in multiple sclerosis and motor neurone disease. J. clin. Path., 18, 641-644.

Cumings, J. N., Thompson, E. J., and Goodwin H. (1968b). Sphingolipids and phospholipids in microsomes and myelin from normal and pathological brains. $J$. Neurochem., 15, 243-248.
Jones, D. P., and Nevin, S. (1954). Rapidly progressive cerebral degeneration (subacute vascular encephalopathy)

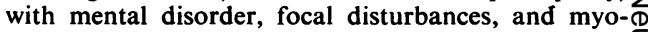
clonic epilepsy. J. Neurol. Neurosurg. Psychiat., 17, 148-159.

Müldner, H. G., Wherrett, J. R., and Cumings, J. N. (1962). Some applications of thin-layer chromatography in the study of cerebral lipids. J. Neurochem., 9, 607-611. T

Nevin, S., McMenemey, W. H., Behrman, S., and Jones, D. P. (1960). Subacute spongiform encephalopathyA subacute form of encephalopathy attributable to vascular dysfunction (spongiform cerebral atrophy) Brain, 83, 519-564.

O'Brien, J. S., and Sampson, E. L. (1965). Fatty acid and $\overrightarrow{\overline{\vec{C}}}$ fatty aldehyde composition of the major brain lipidsin normal human gray matter, white matter and myelin. J. Lipid Res., 6, 545-551.

Stephens, M. C., and Menkes, J. H. (1969). Cerebral lipids in $\overline{\bar{\Phi}}$ Down's syndrome. Develop. Med. Child Neurol., 11, $\mathbb{\Phi}$ 346-352.

Svennerholm, L., and Ställberg-Stenhagen, S. (1968). Changeș in the fatty acid composition of cerebrosides andsulfatides of human nervous tissue with age. J. Lipid. Res., 9, 215-225.

Yanagihara, T., and Cumings, J. N. (1968). Lipid metabolism in cerebral edema associated with human brain tumor: Arch Neurol. (Chic.), 19, 241-247.

Yanagihara, T., and Cumings, J. N. (1969a). Fatty acid composition of cerebrosides and cerebroside sulpha $\omega$ tides in cerebral oedema. Acta. neuropath. (Berl.), 10; 62-67.

Yanagihara, T., and Cumings, J. N. (1969b). Alterations phospholipids, particularly plasmalogens, in demyelination of multiple sclerosis as compared wath that of cerebral oedema. Brain, 92, 59-70. 